\title{
Classical Hodgkin Lymphoma Presenting as Cutaneous and Soft Tissue Mass Lesion: An Enigmatic Presentation Posing a Diagnostic Challenge-A Case Report and Review of Literature
}

\author{
Ayushi Shrivastava ${ }^{1}$ Sandeep Jain ${ }^{1}$ Payal Malhotra \\ ${ }^{1}$ Department of Pediatric Hematology Oncology, Rajiv Gandhi \\ Cancer Institute and Research Centre, New Delhi, India \\ ${ }^{2}$ Department of Pediatric Surgical Oncology, Rajiv Gandhi Cancer \\ Institute and Research Centre, New Delhi, India \\ ${ }^{3}$ Department of Pathology, Rajiv Gandhi Cancer Institute and \\ Research Centre, New Delhi, India
}

Ind J Med Paediatr Oncol 2022;00:1-4.

\author{
Shalini Mishra ${ }^{2}$ Sunil Pasricha ${ }^{3}$ Gauri Kapoor ${ }^{1}$
}

\begin{abstract}
Address for correspondence Gauri Kapoor, MD, PhD, Department of Pediatric Hematology Oncology, Rajiv Gandhi Cancer Institute and Research Centre, Sector 5, Rohini, New Delhi 110085, India (e-mail: kapoor.gauri@gmail.com).
\end{abstract}

\begin{abstract}
Keywords

- cutaneous

- extranodal

- Hodgkin lymphoma

Hodgkin lymphoma $(\mathrm{HL})$ is primarily a nodal disease. Cutaneous involvement of $\mathrm{HL}$ as a presenting feature is extremely rare. Skin involvement is usually seen as a metachronous involvement in the course of disease and is associated with poor prognosis. Primary skin and soft tissue involvement can be construed as nonhematological, inflammatory, or infective etiology. We report a 14-year-old girl with fever, weight loss, lymphadenopathy, and multiple papular lesions over the right chest wall as initial manifestation of $\mathrm{HL}$, posing a diagnostic challenge. In view of stage IVBE, patient was managed with intensive chemotherapy regimen and is currently free of disease at 6 months of follow-up.
\end{abstract}

\section{Introduction}

Hodgkin lymphoma (HL), previously known as Hodgkin disease, is a monoclonal lymphoid neoplasm, originating most often from B lymphocytes. It is characterized by the orderly spread of disease from one lymph node group to another and usually begins in lymph nodes. ${ }^{1}$ Extranodal invasion of adjacent tissue is observed in up to $15 \%$ of cases. ${ }^{2}$ Cutaneous involvement of $\mathrm{HL}$ as a presenting feature is extremely rare. Skin involvement is usually seen as a metachronous involvement in the course of disease and is associated with poor prognosis. We report here an interesting case of $\mathrm{HL}$ in a 14-year-old girl, with fever and lymphadenopathy associated with skin and soft tissue involvement as initial manifestation of HL, which posed a diagnostic challenge. Informed consent was obtained from the parents.

DOI https://doi.org/ $10.1055 / \mathrm{s}-0041-1740441$ ISSN 0971-5851

\section{Case Report}

A 14-year-old female presented with history of intermittent fever, weight loss, and progressively increasing bilateral neck masses over a period of 6 months. She also reported skin lesions over the right chest wall for 3 months and cough associated with breathlessness for about a month. There were no bone pains or symptoms suggestive of aerodigestive tract involvement.

Examination findings revealed the patient to be thin built, anxious, with pallor and mild respiratory distress, bilateral firm, nontender cervical (level 2-4), supraclavicular and axillary lymphadenopathy. The large conglomerate of fused right cervical nodes measured $7 \times 4 \mathrm{~cm}$. There were multiple papules and nodules present over entire right half of chest wall involving breast, infra-axillary, and scapular regions and

(C) 2022. Indian Society of Medical and Paediatric Oncology This is an open access article published by Thieme under the terms of the Creative Commons Attribution-NonDerivative-NonCommercial-License, permitting copying and reproduction so long as the original work is given appropriate credit. Contents may not be used for commercial purposes, or adapted, remixed, transformed or built upon. (https://creativecommons.org/licenses/by-nc-nd/4.0/). Thieme Medical and Scientific Publishers Private Ltd. A-12, Second Floor, Sector -2, NOIDA -201301, India 
extending to right shoulder and neck, few lesions were ulcerative with purulent discharge ( - Fig. 1). Systemic examination revealed reduced air entry over right chest.

She was initially investigated elsewhere and in view of generalized lymphadenopathy and right-sided pleural effusion, she was clinicoradiologically diagnosed as pulmonary tuberculosis and had received 5 months of antitubercular therapy. Her skin lesions were suspected as herpes zoster infection and treated with acyclovir. She was unresponsive to both of the therapies, instead the lymph node mass and skin lesions progressed, for which patient was referred to our institute for further management.

At our institute, patient was investigated and initial complete blood counts, erythrocyte sedimentation rate $(24 \mathrm{~mm})$, liver and renal function tests were normal. Biopsy from the cutaneous lesion revealed unremarkable epidermis with underlying dermis showing infiltrate of polymorphous population of lymphocytes, histiocytes, and eosinophils. Numerous interspersed large neoplastic cells were seen monolobated to polylobated nuclei having vesicular chromatin and prominent nucleoli ( - Figs. 2 A and $\mathbf{B}$ ). On subsequent immunohistochemical staining, the large scattered neoplastic cells were positive for CD30, PAX-5 (heterogenous; -Figs. 2C and D ) while negative for CD20, LCA, CD3, CD15, BCL-6, and EBER-ISH. Overall histopathological features were conclusive of classical HL, nodular sclerosis. The concurrent biopsy from lymph node also revealed HL involvement. Staging investigations revealed the bone marrow (aspirate and biopsy) to be uninvolved by HL, while positron emission tomography computed tomography (PET-CT) scan ( - Fig. $\mathbf{3}$ ) showed metabolically active multiple bilateral cervical,

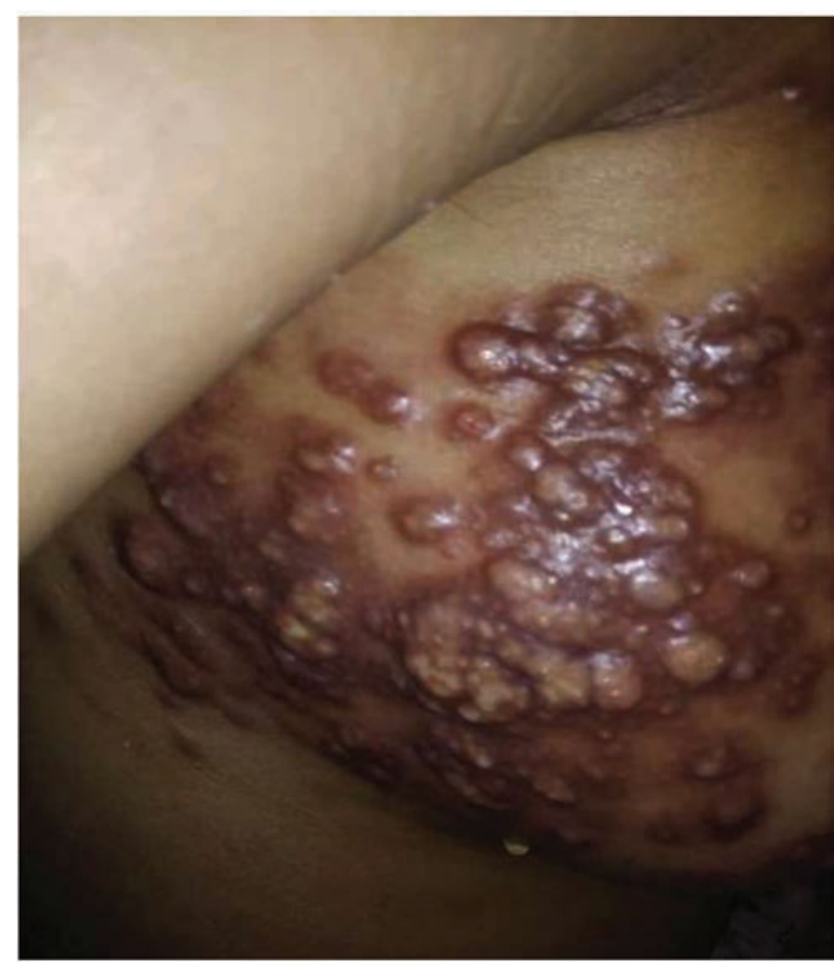

Fig. 1 Multiple papulonodular lesions over right breast and axilla; few lesions show ulceration and purulent discharge.
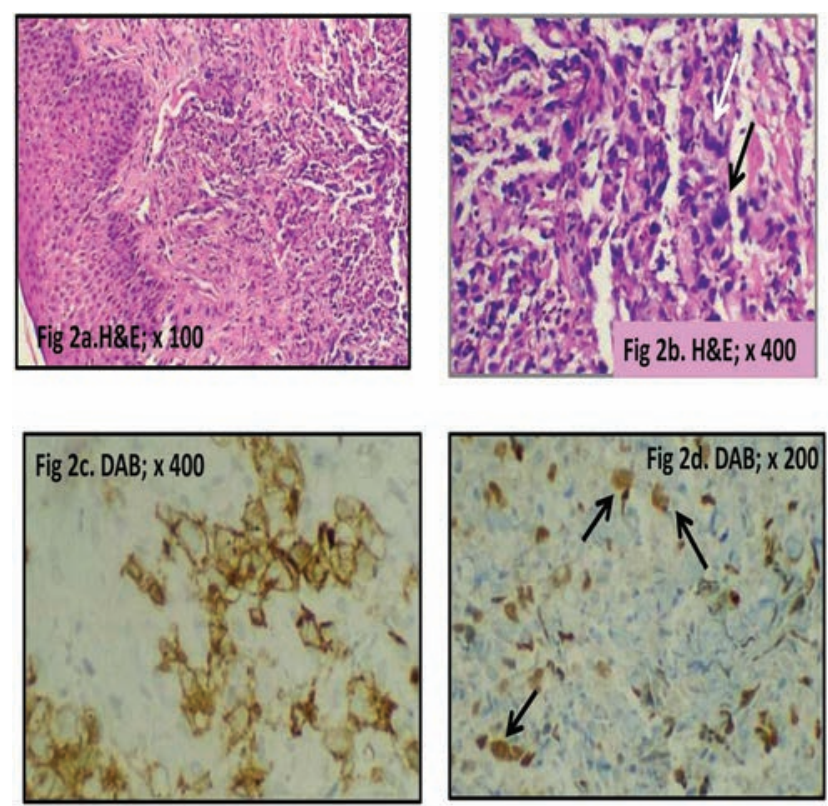

Fig. 2 (A) Section from skin lesion shows unremarkable epidermis with underlying atypical lymphoid infiltrate in dermis. (B) Numerous scattered large neoplastic cells (arrow) with multilobated convoluted nuclei (Reed-Sternberg [RS] cells) seen amid lymphoid infiltrate. (C) The scattered RS cells show strong membranous positivity for CD30. (D) The scattered RS cells (arrow) are also positive for PAX-5. DAB, diaminobenzidine; H\&E, hematoxylin and eosin.
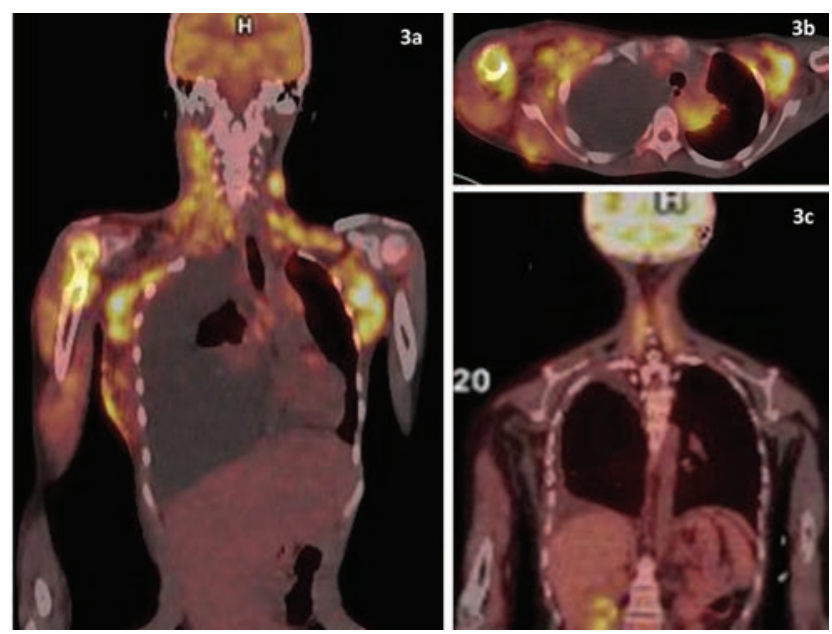

Fig. 3 (A) Whole body positron emission tomography computed tomography scan. Pretreatment image showing metabolically active supradiaphragmatic lymphadenopathy with bone (right humerus), soft tissue (right chest wall), right pleural tissue deposits, and right pleural effusion. (B) Pretreatment cross-sectional image shows contiguous involvement. (C) Posttreatment image (after 4 cycles) reveals complete metabolic response.

supraclavicular, subpectoral, axillary, internal mammary, paratracheal, retrocrural, aortocaval, and para-aortic adenopathy, with extranodal disease involving bone (osteodestructive lesion involving head and shaft of right humerus), soft tissue deposits (right chest wall and right upper arm), right pleural deposits, and right pleural effusion with collapse, hence conforming to stage IVBE. The cross-sectional images reveal that the involvement was contiguous. 
Subsequently, the patient was started on Adriamycin, bleomycin, vinblastine, dacarbazine chemotherapy protocol. However, disease progressed and after one cycle she was put on escalated bleomycin, etoposide, Adriamycin, cyclophosphamide, vincristine, procarbazine and prednisolone chemotherapy. Subsequent evaluation with PET-CT showed partial response (50-60\%) after two cycles and complete response (including skin, except for residual pleural effusion) after four cycles (-Fig. 3C). Hence, further consolidation with high-dose chemotherapy followed by autologous peripheral blood stem cell rescue was undertaken. After the completion of treatment, the patient is free of disease at 6 months of follow-up.

\section{Discussion}

HL is primarily a nodal disease and pattern of spread is usually contiguous, spreading from one LN (lymph nodal) region to the next along the lymphatic system. Extranodal invasion of adjacent tissue is observed in up to $15 \%$ of cases, while hematogenous spread is seen in 5 to $10 \%$ of cases. ${ }^{2}$ We have described an interesting case of HL with multiple extranodal sites of disease with significant involvement of skin and soft tissue.

Cutaneous involvement of HL is extremely rare occurring in 0.5 to $3.4 \%$ of cases and is more frequently reported in non-HL. ${ }^{3,4}$ Although first reported in 1904 by Grosz et al, less than a hundred cases have been reported in literature, and this is the youngest case reported to the best of the author's knowledge (-Table 1) ${ }^{3-10}$ Various types of skin lesions have been reported; these may be nonspecific findings due to paraneoplastic syndrome or vasculitis, like pruritis, urticaria, hyperpigmentation, or ichthyosis, or due to infiltration of skin by disease. ${ }^{5,6}$ The latter may present as nodules, papules, plaques, ulcers, and/or erythroderma, most of which we observed in the present case with biopsy proof of tumor infiltration. ${ }^{7,8}$

Three different pathologic mechanisms have been described in the spread of cutaneous and extranodal HL, of which the most frequent is retrograde lymphatic spread followed by local tumor extension from an underlying nodal or extranodal site. The third mechanism includes hematogenous spread that if extensive has been seen to be associated with poor outcome. ${ }^{8}$ Our patient had multiple supradiaphragmatic nodal disease and extranodal disease involving upper end of right humerus, the skin and soft tissue of the right chest wall (up to the midline), right upper arm, and right pleura.

Skin involvement could also occur from direct extension of same side internal mammary or intercostals lymph nodal disease, which is often present along with chest wall involvement. Involvement of skin by HL is usually associated with more advanced disease as was observed in the present case; patient had stage IV disease that was refractory to first-line chemotherapy. ${ }^{9}$

Interestingly, unilateral lung disease has been seen to occur from involved same-sided hilar adenopathy rather than from hematogenous spread. Pleural effusions occur in $\sim 13 \%$ of cases and are usually negative for malignant cells. ${ }^{8}$

Single osseous involvement is most likely the result of local spread rather than hematogenous process and is usually a late manifestation. It is believed that local extension from adjacent lymph nodes does not alter staging, although extranodal disease resulting from local infiltration (lung, bone, etc.) is regarded as stage IV as in the present case despite absence of widespread dissemination.

We believe that delay in diagnosis occurred in the present case due to two confounding clinical features that were

Table 1 Cutaneous manifestations of Hodgkin lymphoma: review of literature

\begin{tabular}{|c|c|c|c|c|c|c|c|c|}
\hline Author (y) & No & $\begin{array}{l}\text { Age } \\
(y)\end{array}$ & Gender & Symptoms (No) & $\begin{array}{l}\text { Duration } \\
\text { (mo) }\end{array}$ & Stage & Treatment & Response (No) \\
\hline $\begin{array}{l}\text { White and } \\
\text { Patterson } \\
(1985)^{8}\end{array}$ & 16 & $16-63$ & $\begin{array}{l}\text { Male (9) } \\
\text { Female } \\
(7)\end{array}$ & $\begin{array}{l}\text { Lesion on Chest (11) } \\
\text { Neck (3) } \\
\text { Scalp (2) }\end{array}$ & $\begin{array}{l}32.1 \\
\text { (mean) }\end{array}$ & $\begin{array}{l}\text { IV (7) } \\
\text { III (4) } \\
\text { II (5) }\end{array}$ & Multiple regimens & $\begin{array}{l}\text { Death due to disease (11) } \\
\text { Death due to unrelated } \\
\text { cause (1) } \\
\text { Lost to follow-up (4) }\end{array}$ \\
\hline $\begin{array}{l}\text { Jurisić et al } \\
(2005)^{9}\end{array}$ & 1 & 77 & Female & $\begin{array}{l}\text { Nodule arms and } \\
\text { abdomen }\end{array}$ & 6 & II B & CVPP & No complete resolution \\
\hline $\begin{array}{l}\text { Rubenstein and } \\
\text { Duvic }(2006)^{5}\end{array}$ & 3 & & $\begin{array}{l}\text { Male (1) } \\
\text { Female } \\
(2)\end{array}$ & $\begin{array}{l}\text { Nodule over chest } \\
(n=2) \\
\text { Rash on trunk }(n=1)\end{array}$ & - & - & - & - \\
\hline $\begin{array}{l}\text { Isao et al } \\
(2007)^{4}\end{array}$ & 1 & 44 & Male & Nodule on back & 32 & IV B & Multiple regimens & Died \\
\hline $\begin{array}{l}\text { Dhull et al } \\
(2012)^{7}\end{array}$ & 1 & 22 & Female & $\begin{array}{l}\text { Fungating mass over } \\
\text { mid-chest }\end{array}$ & 24 & IV B & $A B V D$ & Disease free \\
\hline $\begin{array}{l}\text { Khawandanah } \\
\text { et al }(2014)^{6}\end{array}$ & 1 & 46 & Male & $\begin{array}{l}\text { Rash on chest and } \\
\text { neck }\end{array}$ & 3 & IVE & AVD/Bend/GCD & Disease free $8 \mathrm{mo}$ \\
\hline $\begin{array}{l}\text { Goyal et al } \\
(2014)^{3}\end{array}$ & 4 & $\begin{array}{l}50 \\
21 \\
25 \\
28\end{array}$ & $\begin{array}{l}\text { Female } \\
\text { Male } \\
\text { Female } \\
\text { Male }\end{array}$ & $\begin{array}{l}\text { Nodules over neck } \\
\text { Ulcer over sternum } \\
\text { Nodule on breast } \\
\text { Rash arms and legs }\end{array}$ & $\begin{array}{l}1 \\
6 \\
12 \\
4\end{array}$ & $\begin{array}{l}\text { IV B } \\
\text { IV B } \\
\text { IV B } \\
\text { IV B }\end{array}$ & $\begin{array}{l}\text { ABVD-RT } \\
\text { ABVD-RT } \\
\text { ABVD } \\
\text { ABVD }\end{array}$ & $\begin{array}{l}\text { Disease free } 3 \mathrm{y} \\
\text { Recurrence in } 6 \text { mo } \\
\text { Disease free } \\
\text { Disease free } 2.5 \mathrm{y}\end{array}$ \\
\hline
\end{tabular}

Abbreviations: ABVD, Adriamycin, bleomycin, vinblastine, and dacarbazine; Bend, bendamustine; CVPP, cyclophosphamide, vincristine, procarbazine, prednisone; GCD, gemcitabine, carboplatin, dexamethasone; No, number of participants; RT, radiotherapy. 
4 Hodgkin Lymphoma Presenting as Cutaneous and Soft Tissue Mass Shrivastava et al.

pleural effusion and skin lesions, both of which are uncommon primary clinical presentations of HL. With modern therapy, advanced HL has 5-year failure-free survival rate of $\sim 80 \%{ }^{10}$ Hence, it is important for the oncologist and pathologist to suspect and diagnose skin lesions due to HL, especially in a pediatric population.

\section{Conclusion}

To conclude, cutaneous involvement, although rare, is a well-recognized manifestation of extranodal HL and can be seen on primary presentation that may mimic nonhematological soft tissue neoplasm. Hence, a diligent histomorphological examination along with intensified chemotherapy regimen is of paramount importance due to distinct therapeutic and prognostic implications.

\section{Declaration of Patient Consent}

The authors certify that they have obtained all appropriate patient consent forms. In the form, the patient has given her consent for her images and other clinical information to be reported in the journal. The patient understands that name and initials will not be published and due efforts will be made to conceal identity, but anonymity cannot be guaranteed.

\section{Financial Support and Sponsorship \\ Nil.}

\section{Conflicts of Interest}

There are no conflicts of interest.

\section{References}

1 Marafioti T, Hummel M, Foss HD, et al. Hodgkin and Reed-Sternberg cells represent an expansion of a single clone originating from a germinal center B-cell with functional immunoglobulin gene rearrangements but defective immunoglobulin transcription. Blood 2000;95(4):1443-1450

2 Guermazi A, BriceP, de KervilerEE, etal. Extranodal Hodgkin disease: spectrum of disease. Radiographics 2001;21(1):161-179

3 Goyal S, Biswas A, Puri T, Gupta R, Muzumder S, Julka PK. Different faces of cutaneous Hodgkin's disease. Indian J Dermatopathol Diagn Dermatol 2014;1:79

4 Isao M, Masanori D, Masatoshi F, Hirokuni, T. Cutaneous involvement in Hodgkin's disease. Int Med J Stage 2007;46:73-74

5 Rubenstein M, Duvic M. Cutaneous manifestations of Hodgkin's disease. Int J Dermatol 2006;45(3):251-256

6 Khawandanah M, Kraus T, Cherry M. Refractory classical Hodgkin lymphoma presenting with atypical cutaneous involvement and diagnosis of ZZ phenotype alpha-1 antitrypsin deficiency. Case Rep Hematol 2014;2014:642868

7 Dhull AK, Soni A, Kaushal V. Hodgkin's lymphoma with cutaneous involvement. BMJ Case Rep 2012;2012:bcr2012007599

8 White RM, Patterson JW. Cutaneous involvement in Hodgkin's disease. Cancer 1985;55(5):1136-1145

9 Jurisić V, Bogunović M, Colovic N, Colović M. Indolent course of the cutaneous Hodgkin's disease. J Cutan Pathol 2005;32(2):176-178

10 Howlader N, Noon AM, Krapcho M, et al. Eds. SEER Cancer Statistics Review, 1975-2017. National Cancer Institute; Bethesda, https://seer.cancer.gov/csr/1975_2017 MDAccessed July 10, 2021 